\title{
Gender difference of androgen actions on skeletal muscle transcriptome
}

\author{
Mayumi Yoshioka, André Boivin, Carl Bolduc and Jonny St-Amand \\ Functional Genomics Laboratory, Department of Anatomy and Physiology, Molecular Endocrinology and Oncology Research Center, Laval University Medical Center (CHUL), \\ Laval University, 2705 Boul. Laurier Ste-Foy, Québec G1V 4G2, Canada \\ (Requests for offprints should be addressed to J St-Amand; Email: jonny.st-amand@crchul.ulaval.ca)
}

\begin{abstract}
Sarcopenia is related to metabolic syndrome in postmenopausal women. Hormone replacement therapies with androgens improve muscle functions by molecular mechanisms that are still unknown, at least partly because the skeletal muscle transcriptome has been less characterized in females. We performed the serial analysis of gene expression method in six experimental groups, intact (male and female), ovariectomy (OVX), OVX+dihydrotestosterone (DHT) injection 1,3 , or $24 \mathrm{~h}$ before kill in mice. The 438 transcript species differentially expressed between gender showed that females had higher expression levels of mRNA related to cytoskeleton/contractile apparatus and mitochondrial processes as well as protein, lipid, and amino acid metabolisms. In females, OVX and DHT modulated 109 and 128 transcript species respectively. OVX repressed transcripts of fast/glycolytic fiber, glycolysis, and glucose transport, whereas all these effects were reversed $3 \mathrm{~h}$ after the DHT injection. Moreover, DHT treatment induced transcripts which reduce intracellular $\mathrm{Ca}^{2+}$ level at early time points. These results may suggest that DHT treatment in OVX mice increases muscle contractility by affecting fiber distribution and intracellular $\mathrm{Ca}^{2+}$ concentration as well as improving glucose metabolism. On the other hand, transcripts of fast/oxidative fiber, oxidative phosphorylation, and ATP production were repressed $24 \mathrm{~h}$ after DHT administration. In our previous study using male mice, transcripts in oxidative phosphorylation and ATP production were induced $24 \mathrm{~h}$ after DHT injection (Yoshioka M, Boivin A, Ye P, Labrie F \& St-Amand J 2006 Effects of dihydrotestosterone on skeletal muscle transcriptome in mice measured by serial analysis of gene expression. Journal of Molecular Endocrinology 36 247-259). These results demonstrate gender differences in $\mathrm{DHT}$ actions on skeletal muscle, and contribute to a precise understanding of the molecular mechanisms of androgen actions in the female skeletal muscle.
\end{abstract}

Journal of Molecular Endocrinology (2007) 39, 119-133

\section{Introduction}

Sex steroids interact with vertebrate androgen or estrogen receptors (ERs). General habitus, shape of body and face, as well as sex hormone levels are similar in prepubertal boys and girls. As puberty progresses, obvious gender differences appear mainly due to a rise in androgen and estrogen levels in men and women respectively. In women, androgen concentrations in plasma are many times higher than the concentration of estrogen, even during reproductive life (Rivera-Woll et al. 2004). Some of these steroids may be considered as prohormones, being converted peripherally to estrogen and other biologically active androgens. This particularly applies to dehydroepiandrosterone and its sulfate, which are sources for testosterone and estrogen throughout life. Circulating testosterone is also a prohormone, which can be converted to the biologically active hormone dihydrotestosterone (DHT) by $5 \alpha$ reductase or to estradiol by aromatase. Testosterone levels decline with age in premenopausal women from the early to the mid-reproductive years and remain stable across the menopausal. After menopause, circulating androgens become the major source of estrogen for women, although the levels are approximately half of those seen in young women (Morley \& Perry 2003). The symptoms of androgen deficiency are hypoactive sexual desire disorder as well as loss of muscle tone and diminished vital energy (Warnock et al. 1997). In contrast to the accepted physiological roles of androgen in males and the importance of diagnosing and treating androgen deficiency in men, the physiological roles of androgen in females are only beginning to be understood (Mazer \& Shifren 2003).

In general, human skeletal muscle tissue comprises $\sim 40-45 \%$ of total body weight, and is one of the most metabolically active tissues in the body. Skeletal muscle fibers contain high levels of both contractile proteins and ATP-producing metabolic enzymes (Yoshioka et al. 2003, 2006), which together make possible the extremely high-energy flux of actively exercising muscle. Moreover, muscle fibers are biochemically and physiologically specialized with different fibers expressing functionally distinct contractile protein 
isoforms and different relative amounts of oxidative versus glycolytic metabolic enzymes (Bottinelli \& Reggiani 2000), which are closely related to the occurrence of obesity and insulin resistance (Lillioja et al. 1987, Tanner et al. 2002). In women, fat-free mass remains relatively stable during premenopausal years, whereas loss of muscle mass, sarcopenia, increases rapidly after menopause transition (Dionne et al. 2000). Androgen increases muscle mass and strength as well as muscle protein anabolism in older women (Notelovitz 2002, Sheffield-Moore et al. 2006), whereas estrogen replacement therapy does not protect against sarcopenia in women (Dionne et al. 2000, Kenny et al. 2003). Thus, androgen replacement may have a role to play in treating disorders of sarcopenia that occur at menopause (Morley 2001).

Sarcopenia causes neuromuscular impairment which leads to falls and fractures, and is associated with obesity and insulin resistance. In healthy men, androgen treatment, particularly DHT, improves insulin sensitivity and decreases plasma leptin level without notable side effects (Simon et al. 2001). However, administration of testosterone to normal and transsexual women or female rats is followed by severe insulin resistance (Polderman et al. 1994, Rincon et al. 1996). One of the reasons for this discrepancy might be explained by the gender difference in the energy metabolism of skeletal muscle. However, the characterization of female skeletal muscle is less often studied than male. In our knowledge, only one study has globally assessed the gender difference of skeletal muscle at mRNA expression level using a microarray technique (Roth et al. 2002). Moreover, no study has compared the effects of androgen on skeletal muscle transcriptome within gender. Therefore, in order to gain insights into the molecular mechanisms of androgen actions on skeletal muscle in postmenopausal women, we have investigated the effect of ovariectomy (OVX) and DHT on global gene expression in gastrocnemius muscle of female mice. Moreover, the results are reanalyzed and compared with our previous study in male mice (Yoshioka et al. 2006).

\section{Materials and methods}

\section{Sample preparation}

The right gastrocnemius muscle was obtained from C57BL6 mice, 12-14 week old, purchased from Charles River Canada Inc. (St Constant, QC, Canada). The animals were housed with light on from 0715 to 1915 , and had access to Lab Rodent Diet No. 5002 (Ren's Feed and Suppliers, ON, Canada) and water ad libitum. No treatment was performed in 26 male and 25 female intact mice. OVX was performed 7 days prior to organ collection in each of 14 mice from the OVX and DHT groups. Mice of the OVX group received an i.p. injection of vehicle solution $(0.4 \%(\mathrm{w} / \mathrm{v})$ Methocel A15LV Premium $/ 5 \%$ ethanol) $24 \mathrm{~h}$ before kill, while a physiological dose of DHT $(0.1 \mathrm{mg} /$ mouse) was injected 1,3 , and $24 \mathrm{~h}$ prior to kill to mice of DHT1h, DHT3h, and DHT24h groups respectively. In total, 26 male and 81 female mice were killed between 0830 and 1230 by cervical dislocation and decapitation under isoflurane anesthesia. The gastrocnemius muscle was sampled from each mouse and pooled together for analysis of the same group to eliminate inter-individual variations and to extract sufficient amount of mRNA. The tissues were stored at $-80{ }^{\circ} \mathrm{C}$ until RNA extraction. All animal experimentation was conducted in accordance with the requirements of the Canadian Council on Animal Care.

We also included our previous study of male mice (Yoshioka et al. 2006) in order to compare gender differences of DHT action. Both male and female mice were purchased at the same time. Moreover, OVX and tissue collection of female mice were performed within 2 days after gonadectomy (GDX) and tissue collection of male mice.

\section{Transcriptome analysis}

The serial analysis of gene expression (SAGE) method was performed as previously described (Velculescu $\mathrm{et} \mathrm{al}$. 1995, St-Amand et al. 2001). Total RNA was isolated by Trizol (Invitrogen Canada Inc). The quality of total RNA was monitored by microcapillary electrophoresis (Bioanalizer 2100, Agilent Technologies, Mississauga, ON, Canada). Polyadenylated RNA was extracted with the Oligotex mRNA Mini Kit (Qiagen Inc.), annealed with the biotin- $-5^{\prime}-\mathrm{T}_{18}-3^{\prime}$ primer and converted to cDNA using the cDNA synthesis kit (Invitrogen Canada Inc). The resulting cDNAs were digested with NlaIII (New England BioLabs Ltd, Pickering, ON, Canada) and the $3^{\prime}$ restriction fragments were isolated with streptavidincoated magnetic beads (Dynal Biotech LLC, Brown Deer, WI, USA) and separated into two populations. Each population was ligated to one of two annealed linkers and extensively washed to remove unligated linkers. The tag beside the most $3^{\prime}$ NlaIII restriction site (CATG) of each transcript was released by digestion with BsmFI (New England BioLabs Ltd). The blunting kit from Takara Bio Inc. (Otsu, Japan) was used for the blunting and ligation of the two tag populations. The resulting ligation products containing the ditags were amplified by PCR and digested with NlaIII. The band containing the ditags was extracted from the $12 \%$ polyacrylamide gel with Spin-X microcentrifuge tube (Fisher, Pittsbergh, PA, USA). The purified ditags were self-ligated to form concatemers using T4 ligase (Invitrogen Canada Inc). The concatemers ranging 
from 500 to $1800 \mathrm{bp}$ were isolated by agarose gel and extracted with gene clean spin (Qbiogene, Montreal, QC, Canada). The resulting DNA fragments were ligated into the SphI site of pUC19 and cloned into UltraMAX DH5 $\alpha$ FT competent cells (Invitrogen Canada Inc). White colonies were picked up with a Q-Bot colony picker (Genetix Ltd, Hampshire, UK). Concatemer inserts were sequenced by the Applied Biosystems 3730 (Foster City, CA, USA).

\section{Bioinformatic analysis}

Sequence files were analyzed using the SAGEana program, a modification of SAGEparser (St-Amand et al., Quebec, PQ Canada; Dinel et al. 2005). In brief, SAGE tags corresponding to linker sequences were discarded and replicate concatemers were counted only once. Identification of the transcripts was obtained by matching the $15 \mathrm{bp}$ (sequence at the last CATG + $11 \mathrm{bp}$ tags) with SAGEmap, UniGene, and GenBank databases on 17th October 2005. A minimum of one expressed sequence tags (EST) with a known polyA tail had to be in the UniGene cluster to identify the last NlaIII site on the corresponding cDNA. We have previously shown that the SAGE method is very reproducible with $r^{2}=0.96$ between two SAGE libraries generated from two cDNA libraries constructed from the same total RNA pool (Dinel et al. 2005). Classification of the transcripts was based upon the updated information of the genome directory (Adams et al. 1995) found at the TIGR web site (http://www.tigr. org/), the SOURCE (http://genome-www5.stanford. edu/cgi-bin/source/sourceSearch), and the OMIM (http://www.ncbi.nlm.nih.gov/) as well as previously published literatures. In total, 1462280 SAGE tags were sequenced, which resulted in 135008 tag species. We also reanalyzed our previous sequence files of male mice in parallel with data from female mice.

\section{Validation by quantitative real-time PCR (QRT-PCR)}

First-strand cDNA was synthesized using $5 \mu \mathrm{g}$ pooled RNA of each experimental group (intact male, intact female, OVX, DHT3h, and DHT24h) in a reaction containing $200 \mathrm{U}$ of Superscript III Rnase H-RT (Invitrogen Canada Inc.), $300 \mathrm{ng}$ oligo-dT $18,500 \mathrm{mM}$ deoxynucleotides triphosphate, $5 \mathrm{mM}$ dithiothreitol, and $34 \mathrm{U}$ human RNase inhibitor (Amersham Pharmacia) in a final volume of $50 \mu$ l. The resulting products after treating with RNase A were purified with Qiaquick PCR purification kits (Qiagen Inc). The cDNA corresponding to $20 \mathrm{ng}$ total RNA was used to perform fluorescent-based real-time PCR quantification using the LightCycler real-time PCR apparatus (HoffmannLa Roche, Natley, NJ, USA). Reagents were obtained from the same company and were used as described by the manufacturer. Reading of the fluorescence signal was taken at the end of the heating to avoid nonspecific signal. A melting curve was performed to assess nonspecific signal. Oligoprimer pairs that allow the amplification of $\sim 250 \mathrm{bp}$ were designed by GeneTools software (Biotools Inc., Edmonton, AB, Canada) and their specificity was verified by blast in GenBank database. Gene name, GenBank accession numbers, and regions used for the primer pairs were the following: myosin heavy polypeptide 2 (Myh2), NM_144961, 5024-5273; fatty acid-binding protein 4 adipocyte (Fabp4), NM_024406, 58-294; and ankyrin 1 erythroid (Ank1), U7392, 1377-1632. The expression levels of mRNA (number of copies/ $\mu$ g total RNA) were calculated using a standard curve of crossing point (Cp) versus logarithm of the quantity. The standard curve was established using known cDNA amounts of $0,10^{2}$, $10^{3}, 10^{4}, 10^{5}$, and $10^{6}$ copies of hypoxanthine guanine phosphoribosyl transferase 1 (Hprt1) and a LightCycler 3.5 program provided by the manufacturer (Hoffmann-La Roche). The QRT-PCR was performed in triplicates. Data are expressed as a ratio to the Hprt1.

\section{Statistical analysis}

We used the comparative count display test to identify the transcripts significantly differentially expressed $(P \leq 0.05)$ between the groups with more than a twofold change (Lash et al. 2000). The data were normalized to 100000 tags for presentation. We also performed $\chi^{2}$ test to identify the significant differences in distributions on total number of transcript species classified in each function (Figs 1 and 2) as well as total number of SAGE tags corresponding to each myosin heavy polypeptide (Myh) isoform $(P<0 \cdot 05)$. The data of QRT-PCR were analyzed by Student's $t$-test to identify the significant gender difference as well as by one-way ANOVA with Dunnett's post hoc test to identify the significant DHT effects in female OVX mice $(P<0 \cdot 05)$.

\section{Results}

\section{Gender difference}

The top 100 abundant transcript species in the gastrocnemius muscle of male and female mice showed the same distribution in each function (Fig. 1). All these transcripts with their expression level are presented in the Supplemental Table 1 at http://jme. endocrinology-journals.org/content/vol39/issue2/. In the differentially expressed transcripts within gender, female muscle showed more upregulated transcript species related to cytoskeleton/contractile apparatus, mitochondrial processes and protein, lipid and amino acid metabolisms as well as functionally less 


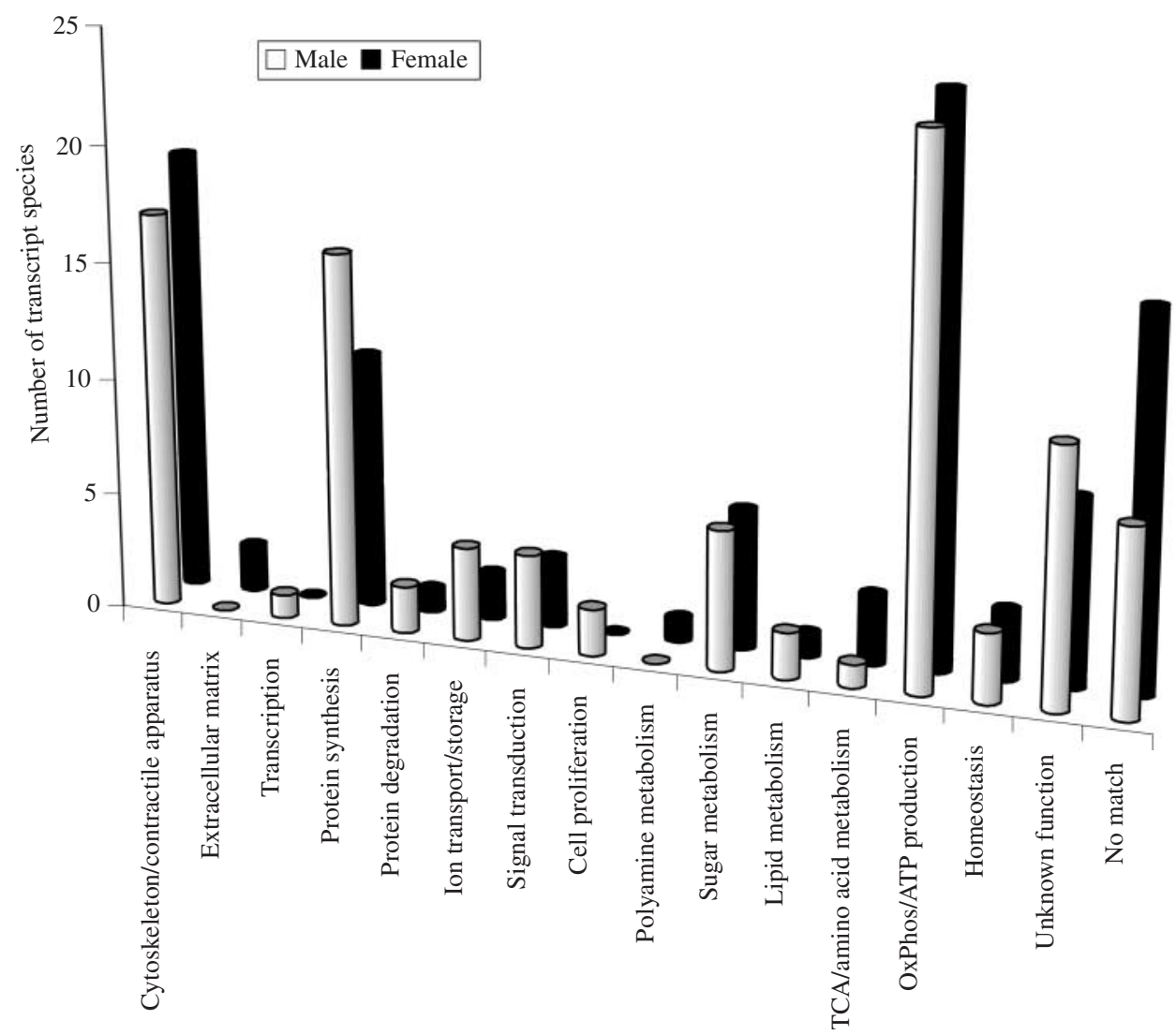

Figure 1 Functional distribution of the top 100 abundant transcripts in the skeletal muscle of male and female mice.

characterized and potentially novel transcripts (Fig. 2). All of 438 differentially expressed transcripts within gender and their modulation by DHT in both male and female mice are presented in the Supplemental Table 2 at http://jme.endocrinology-journals.org/content/ vol39/issue $2 /$. In total, $80 \%$ of differentially expressed transcripts within gender showed higher expression levels in female mice. Approximately $20 \%$ of them were modulated by DHT treatment in male $(n=42)$ and female $(n=47)$ mice, in which only one, namely spermine-binding protein, was commonly but inversely regulated within gender. Interestingly, the modulation by DHT in the transcripts differentially expressed within gender showed a certain pattern of regulation. When the expression level of genes was higher or lower in female than male, DHT down- or up-regulates them in female but up- or down-regulates in male respectively. The exceptions were only three and seven transcripts in female and male respectively. These ten transcripts were related to transcription, cell proliferation, oxidative phosphorylation, and ATP synthesis as well as potentially novel transcripts.

In the cytoskeleton/contractile apparatus, 15 out of 19 transcripts encode proteins which bind to actin and/or localized in $\mathrm{Z}$ band. The SAGE tag number for each Myh in male mice was 35, 5, 184, and 2004 for Myh6, Myh2, Myh1, and Myh4, which correspond to myosin heavy chain isoform I, IIa, IIx/d, and IIb respectively. Their expression levels in female mice were $31,154,119$, and 1337 respectively. Compared with male mice, female mice showed significant higher type IIa and lower type IIb fibers. Concordantly, all the differentially expressed transcripts within gender in the category of muscle fiber type encode proteins expressed in fast type fibers. Interestingly, 8 out of 11 are lower in female, and 2 out of 3 highly expressed transcripts in female, namely Myh2 and tropomyosin $2 \beta$ (Tpm2), are downregulated by DHT treatment in female mice. In the protein metabolism, female mice had higher expression of genes encoding ribosomal proteins as well as proteins functioning in protein transport, chaperone, and protein degradation. In the signal transduction, 22 out of 27 transcripts were related to G-protein signaling pathway including both cyclic AMP (cAMP) and $\mathrm{Ca}^{2+}$ as second messengers as well as insulin receptor substrate 1/2 (IRS1/2) signaling pathway. In the energy metabolism, gene expression profile of female mice indicates higher glycogen synthesis, lipid uptake, $\beta$-oxidation, amino acid 


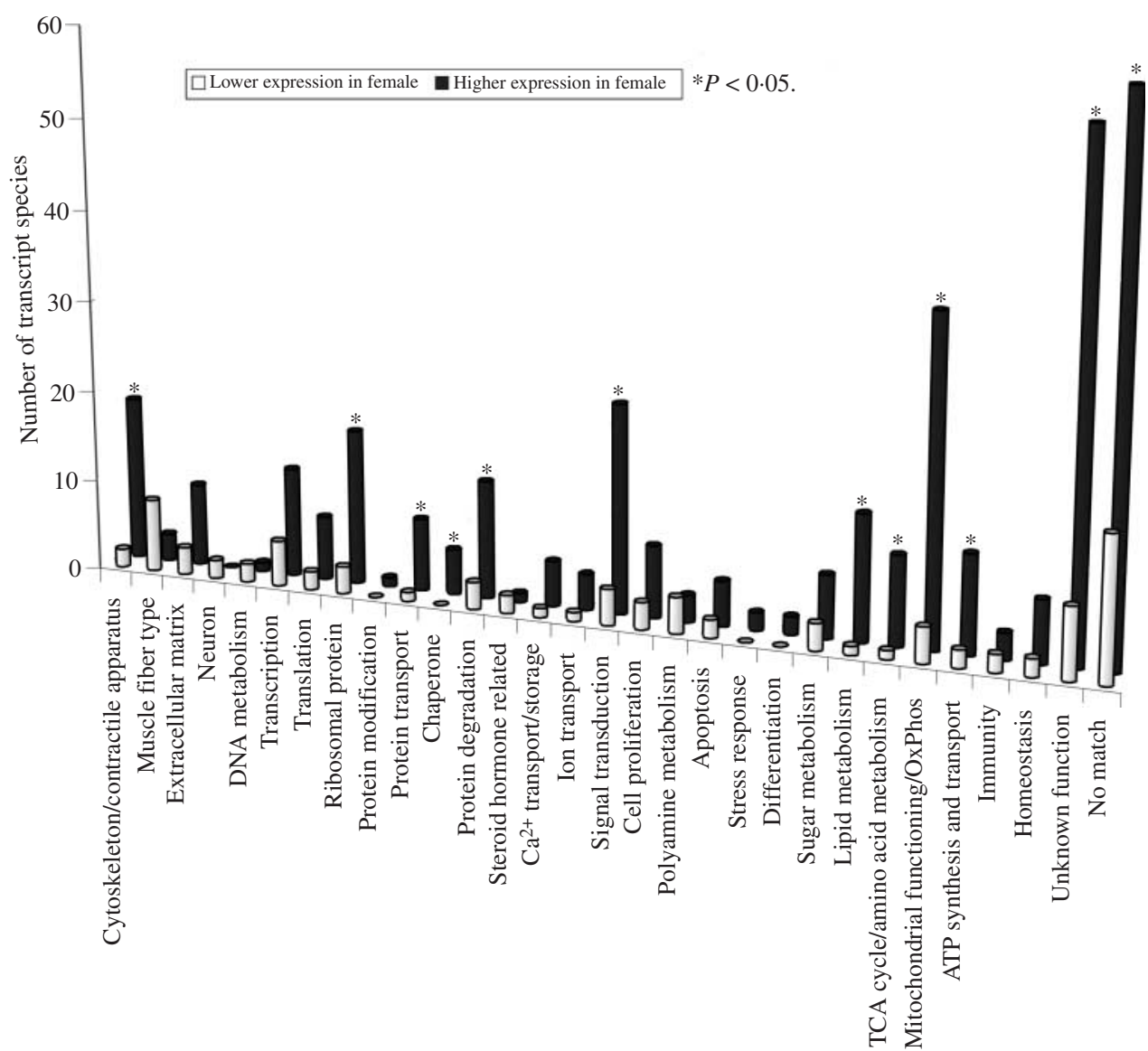

Figure 2 Differentially expressed transcripts in the skeletal muscle of intact female mice when compared with intact male mice according to their function.

utilization, and ATP production, as well as oxidative phosphorylation, especially complexes I and II (Fig. 3).

\section{Effect of OVX and DHT treatment in female muscle}

OVX and DHT modulated 109 and 128 transcript species respectively (Supplemental Tables 3-9 at http://jme. endocrinology-journals.org/content/vol39/issue2/). OVX repressed mRNA of EST Myh4, amino-terminal enhancer of split (Aes), EST cold shock domain protein A, ribosomal protein L15 (Rpl15), ankyrin repeat and SOCS box-containing protein 2 (Asb2), one isoform of EST glyceraldehyde-3-phosphate dehydrogenase (Gapdh), pyruvate kinase muscle (Pkm2), muscle glycogen phosphorylase (Pygm), solute carrier family 2 (facilitated glucose transporter) member 4 (Slc2a4/ Glut4), cytochrome $b$, CUE-domain containing 1, reproductive homeobox on $\mathrm{X}$ chromosome 9, RIKEN 8030451F13, and RIKEN D930010J01 (Fig. 4A), as well as the total number of SAGE tags corresponding to Myh, whereas all these effects were reversed $3 \mathrm{~h}$ after the DHT injection (Fig. 4B). Moreover, DHT treatment induced transcripts which reduce intracellular $\mathrm{Ca}^{2+}$ level at early time points (receptor (calcitonin) activity modifying protein 1, Ramp1; ATPase $\mathrm{Ca}^{2+}$ transporting cardiac muscle fast twitch 1, Atp2a1; calsequestrin 1, Casq1; Fig. 4B). On the other hand, transcripts of fast/oxidative fiber (Myh2), oxidative phosphorylation (NADH dehydrogenase subunit 3, MtNd3; EST NADH dehydrogenase $1 \beta$ subcomplex 1, EST Ndufb1; NADH dehydrogenase Fe-S protein 3, Ndufs3; NADH dehydrogenase $1 \alpha$ subcomplex 7, Ndufa7; cytochrome c oxidase subunit XVII assembly protein homolog, Cox17; cytochrome c oxidase subunit III, MtCo3), and ATP production (ATP synthase $\mathrm{H}^{+}$transporting mitochondrial F1 complex $\alpha$ subunit isoform 1 and $\beta$ subunit, Atp5a1 and Atp5b) were repressed $24 \mathrm{~h}$ after the DHT administration (Fig. 4C).

The androgen-responsive genes were analyzed using a Perl script to identify potential androgen-response element (ARE). Several androgen-regulated genes reported in this study contained a potential ARE in the first $1000 \mathrm{bp}$ of their promoter sequence (Fig. 4 and Supplemental Tables 3-8 at http://jme.endocrinologyjournals.org/content/vol39/issue2/). 


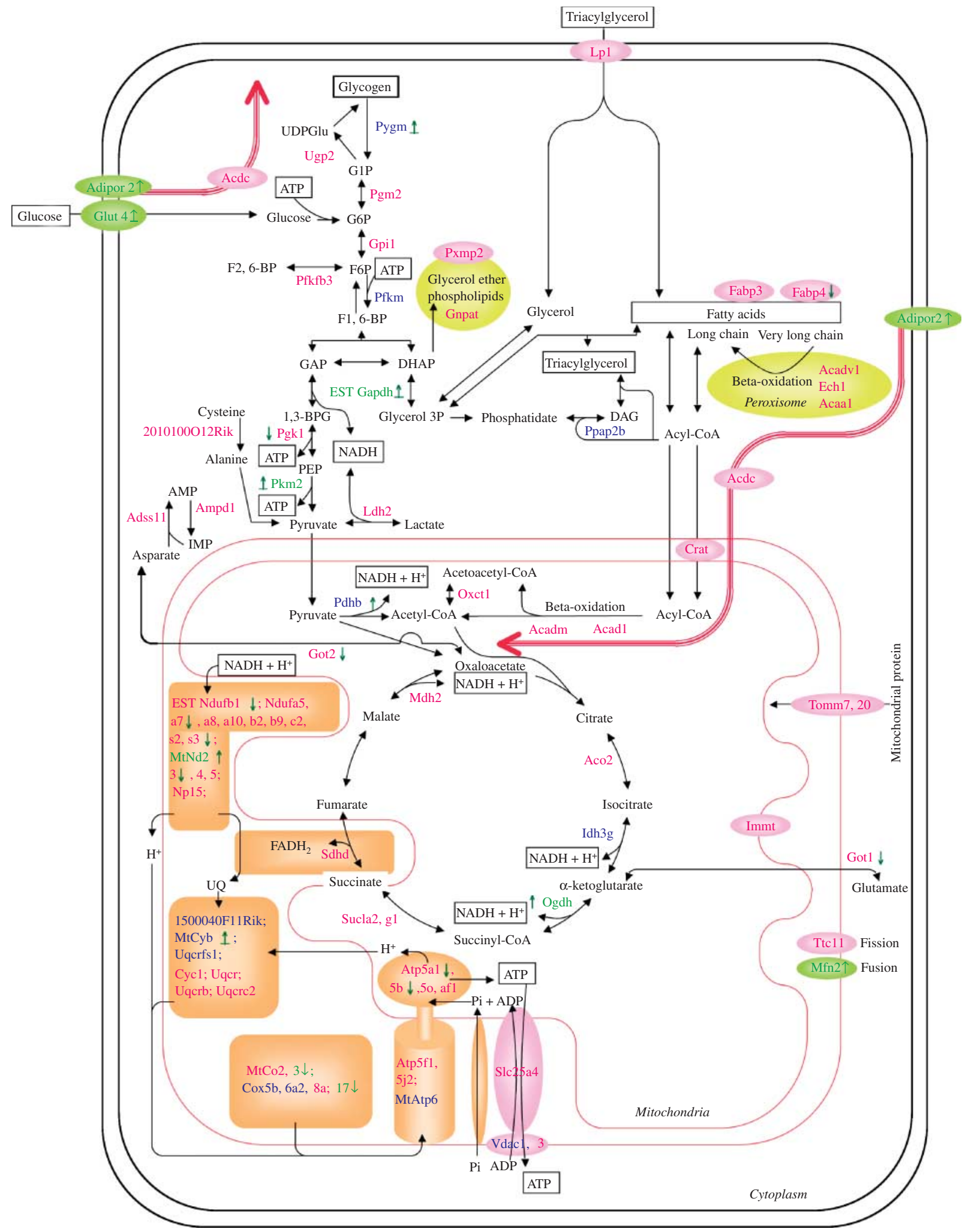


Confirmation of the DHT-regulated genes in the skeletal muscle of female mice by QRT-PCR is shown in Fig. 5. The results of QRT-PCR on Myh2, Fabp4, and Ank1 were concordant with the SAGE results. Moreover, the expression of Fabp4 measured by QRT-PCR showed higher level in intact female mice than in intact male mice $\left(10 \cdot 1 \times 10^{6}\right.$ and $4.0 \times 10^{6}$ copies $/ \mu$ g total RNA respectively) as seen in the SAGE results.

\section{Gender difference in DHT actions}

We have already reported that DHT injection into GDX male mice immediately induces transcripts related to power generation, protein synthesis, mitochondrial function, and satellite cells/myoblasts proliferation, in which only transcripts related to protein synthesis have been repressed at late time point (Yoshioka et al. 2006). In the present study, DHT injection into female GDX mice increased contractility as well as glucose transport and glycogenolysis/glycolysis at the transcriptional level. However, at late time point, the effect on glucose transporter returned to level of GDX and a decrease in transcripts related to mitochondrial function was noted. When we compared each transcripts modulated by DHT between male and female, only nine transcripts were found in both studies, such as 16S rRNA (MtRnr2), cullin 4A (Cul4a), spermine-binding protein (Sbp), cytochrome $c$ oxidase subunit I (MtCo1), NADH dehydrogenase subunit 2 (MtNd2), and four potentially novel transcripts. Of these, two transcripts showed the same regulation by GDX and two others had opposite regulation by DHT.

\section{Discussion}

\section{Gender difference}

The most abundant transcripts in the gastrocnemius muscle of male and female mice showed the same distribution in each function of skeletal muscle, suggesting that the characteristics of skeletal muscle can be defined by abundant transcripts. On the other hand, female muscle showed higher expression levels of transcript species related to cytoskeleton/contractile apparatus, mitochondrial processes and protein, lipid and amino acid metabolisms, as well as functionally less characterized and potentially novel transcripts than male muscle. This can be explained, in part, by the fact that skeletal muscle is a plastic tissue which can adapt to physiological alterations such as circulating hormonal levels as well as female muscle is less characterized when compared with male. In total, $80 \%$ of differentially expressed transcripts within gender showed higher expression levels in female mice. This was the inverse to what has been seen in a previous study (Roth et al. 2002). When these two studies were compared, only

Figure 3 Overview of gender differences in the energy metabolism. The higher and lower gene expressions in the skeletal muscle of female mice when compared with male mice are shown in red and blue characters respectively. The up- and down-regulated transcripts by dihydrotestosterone (DHT) treatment in ovariectomized (OVX) mice are shown as green arrows. Underlining of the green arrow shows inverse modulation by OVX compared to intact mice. DHT-responsive transcripts in OVX female mice were also shown in green characters. Red arrow represents stimulation of pathways by proteins encoded by certain transcripts. Abbreviation: 1,3-BPG, 1,3-bisphosphoglycerate; 1500040F11Rik, RIKEN 1500040F11; 2010100012Rik, nitrogen fixation gene 1; Acaa1, acetyl-coenzyme A acyltransferase 1; Acadl, $\mathrm{m}$, vl, acetyl-coenzyme $\mathrm{A}$ dehydrogenase long-chain, medium chain, and very long chain; Acdc, adiponectin; Aco2, aconitase 2 mitochondrial; Adipor2, adiponectin receptor 2; Adssl1, adenylosuccinate synthetaselike 1; AMP, adenosine monophosphate; Ampd1, AMP deaminase 1 isoform M; ATP, adenosine triphosphate; Atp5a1, 5b, 5f1, 5j2, 5o, af1, ATP synthase $\mathrm{H}^{+}$transporting mitochondrial $\mathrm{F} 1$ complex $\alpha$ subunit isoform $1, \mathrm{~F} 1$ complex $\beta$ subunit, F0 complex subunit $\beta$ isoform 1, F0 complex subunit $\mathrm{f}$ isoform 2, $\mathrm{F} 1$ complex $\mathrm{O}$ subunit, $\mathrm{F} 1$ complex assembly factor 1; Cox $5 \mathrm{~b}, 6 \mathrm{a} 2,8 \mathrm{a}, 17$, cytochrome $c$ oxidase subunit Vb, subunit VI a polypeptide 2, subunit VIIla, subunit XVII assembly protein homolog; Crat, carnitine acetyltransferase; Cyc1, cytochrome c-1; DAG, diacylglycerol; DHAP, dihydroxyacetone phosphate; Ech1, enoyl coenzyme A hydratase 1 peroxisomal; EST, expressed sequence tags; F1,6-BP, fructose 1,6-bisphosphate; F2,6-BP, fructose 2,6-bisphosphate; F6P, fructose 6-phosphate; Fabp3,4, fatty acid-binding protein 3, 4; G1P, glucose 1-phosphate; G6P, glucose 6-phosphate; GAP, glyceraldehyde 3-phosphate; Gapdh, glyceraldehyde-3-phosphate dehydrogenase; Glut4/SIc2a4, solute carrier family 2 (facilitated glucose transporter) member 4; Glycerol 3P, glycerol 3-phosphate; Gnpat, glyceronephosphate O-acyltransferase; Got1, 2, glutamate oxaloacetate transaminase 1 soluble, 2 mitochondrial; Gpi1, glucose phosphate isomerase 1; Idh3g, isocitrate dehydrogenase $3\left(\mathrm{NAD}^{+}\right) \gamma$; Immt, inner membrane protein mitochondrial; IMP, inosine monophosphate; Ldh2, lactate dehydrogenase 2, B chain; Lpl, lipoprotein lipase; Mdh2: malate dehydrogenase 2 NAD mitochondrial; MtAtp6: ATP synthase F0 subunit 6; MtCo2,3, cytochrome coxidase subunit II, subunit III; MtCyb, cytochrome $b$; MtNd2, 3, 4, 5, NADH dehydrogenase subunit 2, 3, 4, 5; NADH, NADH (reduced); Ndufa5, a7, a8, a10, b1, b2, b9, c2, s2, s3, NADH dehydrogenase $1 \alpha$ subcomplex 5, $1 \alpha$ subcomplex $7,1 \alpha$ subcomplex $8,1 \alpha$ subcomplex $10,1 \beta$ subcomplex $1,1 \beta$ subcomplex $2,1 \beta$ subcomplex 9,1 subcomplex unknown 2, Fe-S protein 2, Fe-S protein 3; Np15, nuclear protein 15.6; Ogdh, oxoglutarate dehydrogenase; Oxct1, 3-oxoacid CoA transferase 1; Pdhb, pyruvate dehydrogenase $\beta$; PEP, phosphoenolpyruvate; Pfkfb3, fructose-2,6-biphosphatase 3; Pfkm, phosphofructokinase; Pgk1, phosphoglycerate kinase 1; Pgm2, phosphoglucomutase 2; Pkm2, pyruvate kinase muscle; Ppap2b, phosphatidic acid phosphatase type 2B; Pxmp2, peroxisomal membrane protein; Pygm, muscle glycogen phosphorylase; Sdhd, succinate dehydrogenase complex subunit D integral membrane protein; Slc25a4, solute carrier family 25 (mitochondrial carrier, adenine nucleotide translocator) member 4; Sucla2, g1, succinate-coenzyme A ligase ADP-forming $\beta$ subunit, GDP-forming $\alpha$ subunit; Tomm7, 20, translocase of outer mitochondrial membrane 7 homolog, 20 homolog; Ttc11, tetratricopeptide repeat domain 11; UDPGlu, uridine diphosphate glucose; Ugp2, UDP-glucose pyrophosphorylase 2; Uqcr, b, c2, fs1, ubiquinol-cytochrome $c$ reductase subunit, binding protein, core protein 2 , Rieske iron-sulfur polypeptide 1; Vdac1,3, voltage-dependent anion channel 1 , 3. 

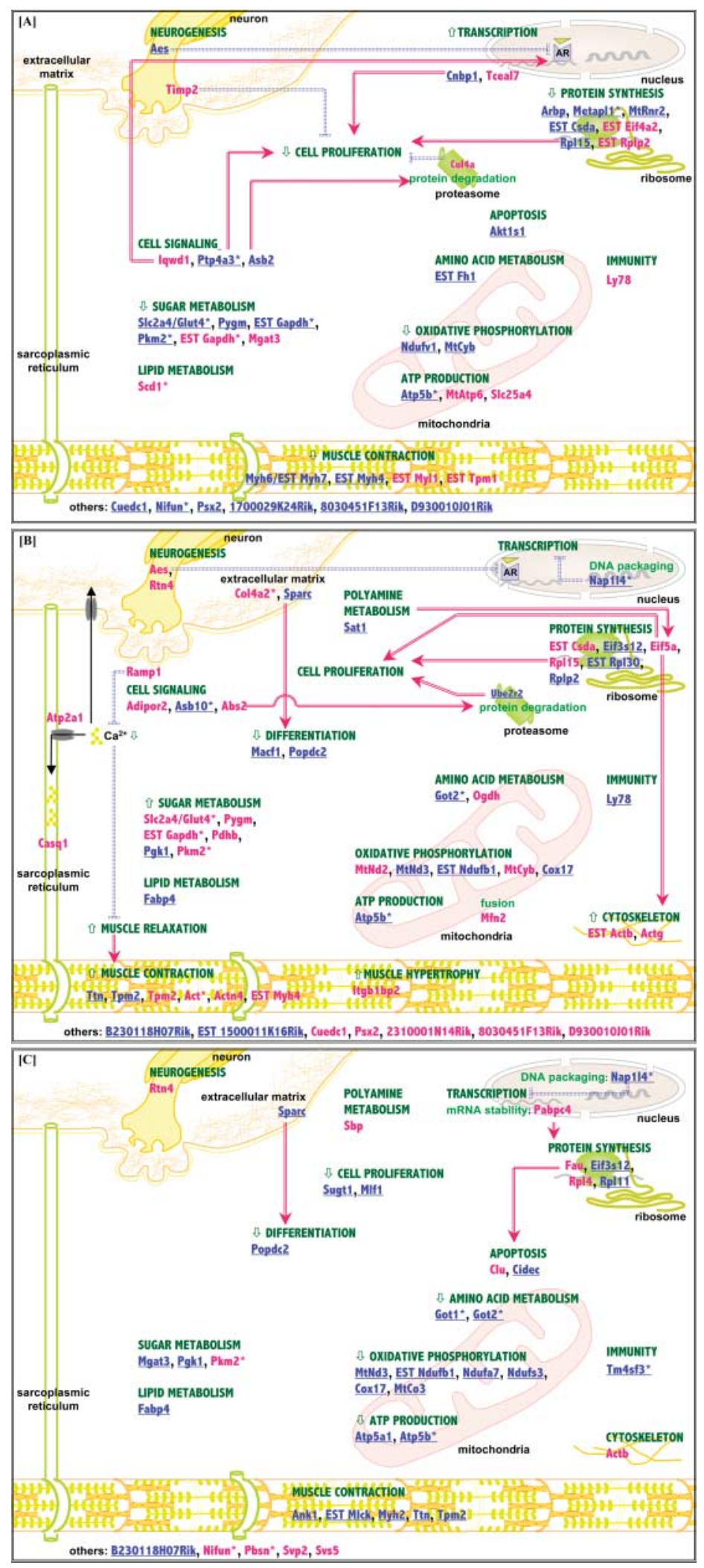
four genes were available for direct comparison. In which three genes, namely transcription elongation factor B (SIII) polypeptide 2, plectin 1, and ubiquitinconjugating enzyme E2G 2, showed the same gender difference. The only gene showing the opposite result between these two studies was Fabp4. Thus, we performed QRT-PCR analysis on this gene, and confirmed the higher expression level in female mice. One of the reasons why we found only a few common genes between these two studies is the different methods used for global gene expression analysis. The results of microarray depend on genes that have been spotted on, whereas the SAGE does not need to select genes prior to the analysis. Thus, the SAGE method does not have a bias on the results obtained. Indeed, the microarray of the previous study (Roth et al. 2002) contains only $\sim 4000$ known genes in which only $\sim 1000$ genes are expressed above background, whereas our data contain 135008 transcripts species including uncharacterized and novel transcripts. These resulted in 210 differentially expressed transcripts by gender in the former and 438 transcripts in the later. Moreover, their microarray does not contain mitochondrialencoded genes as well as functionally uncharacterized and unknown genes, which accounted for $37 \%$ of the gender regulated transcripts in the present study. Furthermore, the microarray can be more sensitive to detect the differences in some low abundant genes. The previous study (Roth et al. 2002) has also compared their differentially expressed genes in age with the SAGE study of Welle et al. (2000), in which only seven genes have been available for direct comparison. Thus, these results support our explanation that their microarray and the SAGE detect different transcripts because of the distinct strategy used to measure the gene expression. Nevertheless, the results from these two studies complement each other to understand the gender differences of skeletal muscle.

In the differentially expressed transcripts within gender, no gene had the same regulation by DHT within gender and the pattern of modulation by DHT was opposed within gender. This clearly shows that responses to androgen in the skeletal muscle are different between male and female, even though all mice are GDX for 1 week and the same dose of DHT was used instead of testosterone in order to avoid effects of estrogen which can be converted from testosterone by aromatase.

The fiber type composition calculated from the SAGE tag number of each Myh was similar as the previous studies from the same strain of mice (Allen et al. 2001, Pellegrino et al. 2005). Compared with male mice, female mice showed significant higher fast/oxidative fiber and lower fast/glycolytic fiber. Although DHT decreased transcripts of fast/oxidative fiber (Myh), the expression level remained higher in female than male.

Figure 4 Effects of ovariectomy (OVX) and dihydrotestosterone (DHT) treatment on the skeletal muscle transcriptome in female mice. The up- and downregulated transcripts by OVX and DHT treatment in OVX mice are shown in red and blue (underlined) characters respectively. The solid and dot lines represent activation/induction and inhibition respectively. Asterisk $\left({ }^{\star}\right)$ represents genes containing androgen response element. (A) Effects of OVX on the skeletal muscle transcriptome. (B) Early effects of DHT treatment (DHT1h and DHT3h). (C) Late effects of DHT treatment (DHT24h). Abbreviation: 1500011K16Rik, 1700029K24Rik, 2310001N14Rik, 8030451F13Rik, RIKEN 1500011K16, 1700029K24, 2310001N14, 8030451F13; Actb, g, actin $\beta$ cytoplasmic, $\gamma$ cytoplasmic 1; Actn4, actinin $\alpha$ 4; Adipor2, adiponectin receptor 2; Aes, amino-terminal enhancer of split; Akt1s1, AKT1 substrate 1; Ank1, ankyrin 1 erythroid; AR, androgen receptor, Arbp, acidic ribosomal phosphoprotein P0; Asb2,10, ankyrin repeat and SOCS box-containing protein 2, 10; Atp2a1, ATPase $\mathrm{Ca}^{++}$transporting cardiac muscle fast twitch 1; Atp5a1,b, ATP synthase $\mathrm{H}^{+}$ transporting mitochondrial F1 complex $\alpha$ subunit isoform 1, $\beta$ subunit; B230118H07Rik, RIKEN B230118H07; Casq1, calsequestrin 1; Cidec, cell death-inducing DFFA-like effector c; Clu, clusterin; Cnbp1, cellular nucleic acid binding protein 1; Col4a2, procollagen type IV $\alpha 2$; Cox17, cytochrome $c$ oxidase subunit XVII assembly protein homolog; Csda, cold shock domain protein A; Cuedc1, CUE domain containing 1; Cul4a, cullin 4A; D930010J01Rik, RIKEN D930010J01; Eif3s12, 4a2, 5a, eukaryotic translation initiation factor 3 subunit 12, 4A-II, 5A; EST, expressed sequence tags; Fabp4, fatty acid binding protein 4 adipocyte; Fau, Finkel-Biskis-Reilly murine sarcoma virus (FBR-MuSV) ubiquitously expressed; Fh1, fumarate hydratase 1; Gapdh, glyceraldehyde-3-phosphate dehydrogenase; Got1,2, glutamate oxaloacetate transaminase 1 soluble, 2 mitochondrial; lqwd1, IQ motif and WD repeats 1; Itgb1bp2, integrin $\beta 1$ binding protein 2; Ly78, lymphocyte antigen 78; Macf1, microtubule-actin crosslinking factor 1; Metapl1, methionine aminopeptidase-like 1; Mfn2, mitofusin 2; Mgat3, mannoside acetylglucosaminyltransferase 3; Mlck, myosin light chain kinase; Mlf1, myeloid leukemia factor 1; MtAtp6, ATP synthase F0 subunit 6; MtCo3, cytochrome $c$ oxidase subunit III; MtCyb, cytochrome $b$; MtNd2,3, NADH dehydrogenase subunit 2, 3; MtRnr2, 16S rRNA; Myh2, 4, 6/7, myosin heavy polypeptide 2, 4, 6/7; Myl1, myosin light polypeptide 1; Nap1/4, nucleosome assembly protein 1-like 4; Ndufa7, b1, s3, v1, NADH dehydrogenase $1 \alpha$ subcomplex 7, 1 \& subcomplex 1, Fe-S protein 3, flavoprotein 1; Nifun, NifU-like N-terminal domain containing; Ogdh, oxoglutarate dehydrogenase; Pabpc4, poly(A)-binding protein cytoplasmic pseudogene and cytoplasmic 4 isoform 1; Pbsn, probasin; Pdhb, pyruvate dehydrogenase $\beta$; Pgk1, phosphoglycerate kinase 1; Pkm2, pyruvate kinase muscle; Popdc2, popeye domain containing 2; Psx2, reproductive homeobox on X chromosome 9; Ptp4a3, protein tyrosine phosphatase 4a3; Pygm, muscle glycogen phosphorylase; Ramp1, receptor (calcitonin) activity modifying protein 1; Rpl4, I11, I15, I30, Ip2, ribosomal protein L4, L11, L15, L30, large P2; Rtn4, reticulon 4; Sat1, spermidine/spermine N1-acetyl transferase 1; Sbp, spermine-binding protein; Scd1, stearoylcoenzyme A desaturase 1; Slc25a4, solute carrier family 25 (mitochondrial carrier adenine nucleotide translocator) member 4; Slc2a4/Glut4, solute carrier family 2 (facilitated glucose transporter) member 4; Sparc, secreted acidic cysteine rich glycoprotein; Sugt1, SGT1 suppressor of G2 allele of SKP1; Svp2, seminal vesicle protein 2; Svs5, seminal vesicle secretion 5; Tceal7, transcription elongation factor A (SII)-like 7; Timp2, tissue inhibitor of metalloproteinase 2; Tm4sf3, transmembrane 4 superfamily member 3; Tpm1, 2, TPM1 $\alpha$, $2 \beta$; Ttn, titin; Ube2r2, ubiquitin-conjugating enzyme E2R 2. 

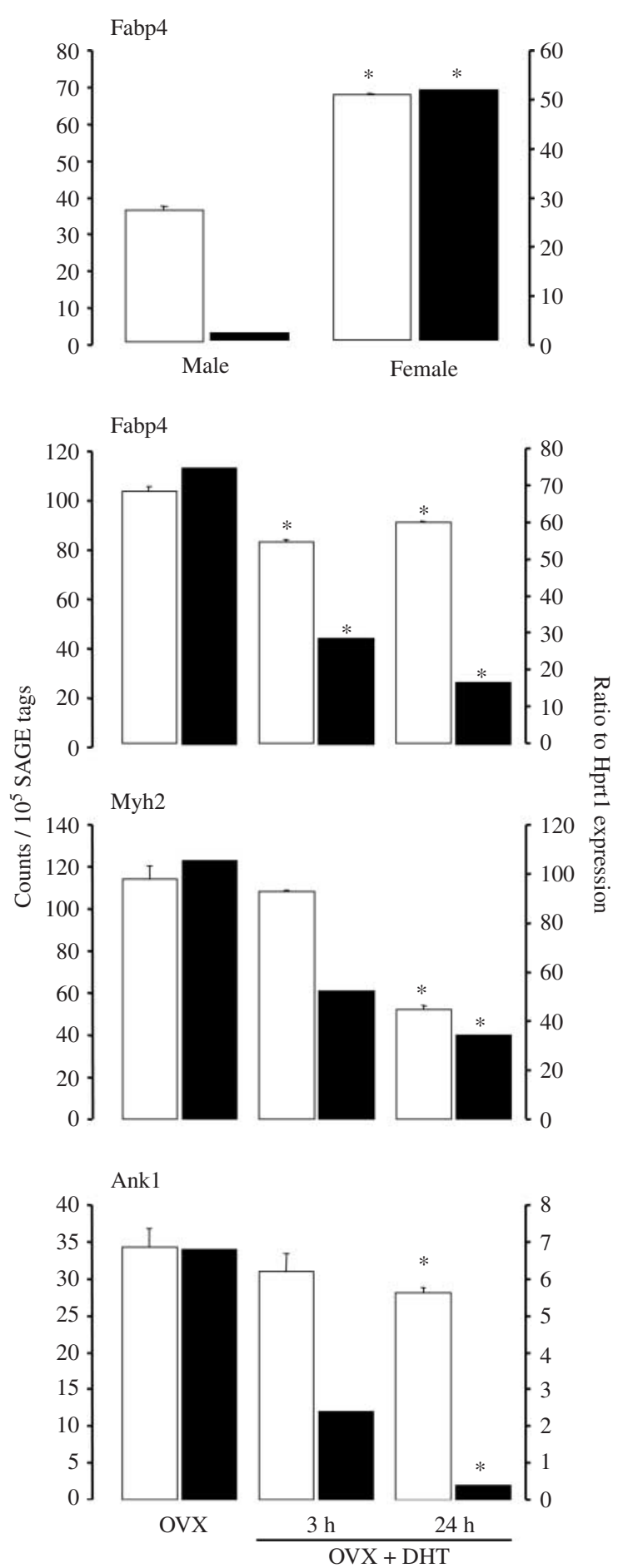

Figure 5 Confirmation of serial analysis of gene expression (SAGE) data by quantitative real-time PCR (QRT-PCR). Asterisk (*) represents a significant gender difference or significant $D H T$ actions when compared with OVX mice $(P<0 \cdot 05)$. Open and closed bars represent data from QRT-PCR and SAGE respectively. Abbreviation: Ank1, ankyrin 1; Fabp4, fatty acid-binding protein 4 adipocyte; Hprt1, hypoxanthine guanine phosphoribosyl transferase 1; Myh2, myosin heavy polypeptide 2; OVX, ovariectomy.
This was reflected in the gene expression profile of the energy metabolism, which shows higher glycogen synthesis, lipid uptake, $\beta$-oxidation, amino acid utilization and ATP production, as well as oxidative phosphorylation in female mice.

In the signal transduction, 22 out of 27 transcripts were related to G-protein signaling pathway including both cAMP and $\mathrm{Ca}^{2+}$ as second messengers as well as IRS1/2 signaling pathway, which lead to the modulation of muscle growth and energy metabolism. In particular, the present study showed the higher expression of protein kinase AMP-activated $\gamma 3$ non-catalytic subunit (Prkag3) and tripartite motifcontaining 63 (Trim63) in female mice. The Prkag3 increases fatty acid oxidation, glucose uptake, glycolysis, and glycogen synthesis (Nilsson et al. 2006), most of which were concordant with the gene expression profile of energy metabolism in female mice seen in the present study. The Trim63 is known to induce muscle wasting (Glass 2005). Aside from the G protein and IRS1/2 signaling pathways, female muscle showed the lower expression of parkinson disease 7 which is a positive regulator of androgen receptor (AR) transcriptional activity (Takahashi et al. 2001). In the steroid hormone related, female muscle showed the higher expression of estrogen related receptor $\alpha$ which is a key regulator of mitochondrial biogenesis and oxidative metabolism (Villena et al. 2007). Taken together, these results well support a general phenotype of female skeletal muscle.

\section{Effects of OVX}

$\mathrm{AR}$ is a member of the superfamily of ligand-inducible transcription factors and mediates the biological actions of androgen. In the present study, OVX downregulated Aes which inhibits AR-driven transcription by directly targeting the basal transcription machinery (Yu et al. 2001) and cellular nucleic acid-binding protein 1 (Cnbp1) which represses sterol-mediated repression of gene transcription (Rajavashisth et al. 1989), while it upregulated IQ motif and WD repeats 1 (Iqwd1), which is a ligand-dependent coactivator of AR (Tsai et al. 2005) and transcription elongation factor A (SII)-like 7. These results indicate an increased transcription by OVX. In addition, Aes is also involved in neurogenesis and muscle development (van Hateren et al. 2005). Interestingly, Magnusson et al. (2005) have reported that denervation represses protein tyrosine phosphatase $4 a 3$ (Ptp4a3) gene expression, which was also observed after OVX in the present study.

OVX resulted in a reduction in the expression of five genes related to protein synthesis, while inducing two ESTs. Moreover, OVX upregulated Cul4a, a histone ubiquitin ligase, which participates in the cellular response to DNA damage (Wang et al. 2006b), whereas 
it downregulated Asb2 which reconstitutes an E3 ubiquitin ligase complex (Heuze et al. 2005). Thus, these results suggest that OVX decreases protein synthesis but not protein degradation.

In the present study, OVX downregulated Cnbp1, Rpl15, and Ptp4a3, all of which stimulate cell proliferation (Shimizu et al. 2003, Liang et al. 2006, Wang et al. $2006 a$ ), whereas it upregulated tissue inhibitor of metalloproteinase 2 (Timp2) which inhibits endothelial cell proliferation and angiogenesis (Seo et al. 2003). Although OVX also induced Cul4a which promotes $\mathrm{G}_{1}$ cell cycle progression (Higa et al. 2006), it suppressed AKT1 substrate 1 (Akt1S1), a proline-rich AKT substrate (Kovacina et al. 2003). The AKT is known to inhibit apoptosis and stimulate cellular growth. Thus, overall, OVX may reduce growth of skeletal muscle.

In addition to cellular growth, AKT is also implicated in insulin signaling which stimulates GLUT4 translocation and glucose transport. Concordant with the modulation of Akt1s1 by OVX, Slc2a4/Glut4, Pygm, Pkm2, and one isoform of EST glyceraldehyde-3phosphate dehydrogenase (Gapdh) were also downregulated by OVX. Type I and IIa fibers have a higher GLUT4 protein expression (Hayasaki et al. 2001), whereas type IIb fiber has a higher GAPDH (Hallauer \& Hastings 2002). The repression of both Myh6/EST Myh7 and EST Myh4 after OVX may be reflected in the reduction of Slc2a4/Glut4 and one isoform of EST Gapdh respectively. Although OVX decreased total SAGE tag number of Myh by $40 \%$, the ratio of fast:slow fibers was increased by $151 \%$. Other transcripts induced by OVX in muscle fiber type are encoding the fast isoforms (EST myosin light polypeptide 1 and EST tropomyosin $1 \alpha$ ). Moreover, OVX downregulated one and two transcripts encoding enzymes in TCA cycle and oxidative phosphorylation. Taken together, OVX may reduce glucose uptake and glucogenolysis/glycolysis as well as oxidative phosphorylation, which correspond well to the changes in fiber type distribution.

\section{Early response to DHT injection}

The main findings of early responses to DHT injection are the following: 1) 14 OVX-repressed transcripts were reversed by DHT treatment, especially the transcripts related to fast/glycolytic fiber (EST Myh4), glucose transport (Slc2a4/Glut4), and glycogenolysis/glycolysis (Pygm, EST Gapdh, and Pkm2); and 2) DHT induced transcripts which reduce intracellular $\mathrm{Ca}^{2+}$ level (Ramp1, Atp2a1, and Casq1).

Total SAGE tag number corresponding to Myh was increased by $93 \%$ immediately after the DHT injection, and the increase in total Myh4 tag number was $109 \%$. On the other hand, elastic filament titin (Ttn), which maintains resting tension and imposes a substantial braking force during contraction, was downregulated by DHT. Thus, the modulation of these transcripts might result in an increased muscle contractility. It has been demonstrated that recruitment of AR via serum response factor facilitates skeletal actin $\alpha$ (Acta) gene expression (Vlahopoulos et al. 2005). In the present study, Acta and two other isoforms, Actb and Actg, as well as transcripts corresponding to actin-binding protein (actinin $\alpha 4$ and Tpm2) were all induced by DHT. Moreover, the reduction of intracellular $\mathrm{Ca}^{2+}$ level leads to relaxation of skeletal muscle, which in turn increases muscle contraction (Zhao et al. 2003). In addition, integrin $\beta 1$-binding protein 2 , which leads to muscle hypertrophy in a response to pressure overload was also upregulated by DHT. These results indicate an induction of muscle growth along with a higher contractile ability immediately after the DHT injection. On the other hand, the early response to DHT in neurogenesis is unclear, since DHT-induced transcripts related to both neurogenesis (Aes; van Hateren et al. 2005) and neurite growth-inhibitory activity (reticulon 4; Jokic et al. 2006).

In addition to Slc2a4/Glut4, Pygm, EST Gapdh, and Pkm2, DHT also increased pyruvate dehydrogenase $\beta$ and adiponectin receptor 2 (Adipor2). Recently, Yamauchi et al. (in press) have reported that overexpression of Adipor2 in the liver of $d b / d b$ mice markedly improves insulin sensitivity and resistance as well as fatty acid oxidation, whereas Adipor2 knockout mice shows reduced insulin sensitivity. Therefore, DHT treatment might have a beneficial effect on glucose metabolism in OVX mice. The present study also noted an induction of mitofusin 2 (Mfn2) immediately after the DHT injection. This mitochondrial membrane protein participates in mitochondrial fusion in mammalian cells. Mfn2 has been reported to increase glucose oxidation, mitochondrial membrane potential, and cell respiration (Bach et al. 2003). However, we neither find any coordinate modulation of transcripts in TCA cycle nor oxidative phosphorylation immediately after the DHT injection.

Spermidine/spermine N1-acetyl transferase 1 (Sat1) is the key enzyme responsible for interconversion of spermine and spermidine to spermidine and putrescine respectively. Eukaryotic translation initiation factor 5A (Eif5a) is the only protein in nature that contains hypusine, an unusual amino acid derived from the modification of lysine by spermidine. The depletion of Eif5a leads to a striking change of actin dynamics (disappearance of actin cables) as well as a complete cell cycle arrest at $\mathrm{G}_{1}$ phase (Chatterjee et al. 2006). Both Sat1 and Eif5a as well as Rpl15 and ubiquitinconjugating enzyme E2R 2 (Ube2r2) were modulated by DHT treatment. Ube2r2 is highly homologous to cell division cycle 34 (Cdc34; Sun et al. 1997). Antisense oligonucleotides targeting Cdc34 downregulate its 
expression and inhibit the degradation of p2 $7^{\mathrm{Kip} 1}$ (Butz et al. 2005). Thus, all of these transcripts are also involved in cellular proliferation (Butz et al. 2005, Nishimura et al. 2005, Wang et al. 2006a). Secreted acidic cysteine rich glycoprotein (Sparc) is an extracellular $\mathrm{Ca}^{2+}$-binding glycoprotein associated with morphogenesis and remodeling of various tissues. The $\mathrm{Ca}^{2+}$ chelator inhibits Sparc gene expression and $\mathrm{Ca}^{2+}$ inophore rapidly induces transcription of Sparc (Cho et al. 2000). The expression of Sparc is known to be upregulated during the differentiation of myoblasts (Cho et al. 2000). Moreover, microtubule-actin crosslinking factor 1 (Macf1) is induced during formation of fused myotubes during differentiation (Sun et al. 1999), and pop-eye domain containing 2 (Popdc2) is a marker of myocardial differentiation (Breher et al. 2004). Therefore, the repressions of Sparc, Macf1, and Popdc2 by DHT suggest a reduced differentiation immediately after the DHT injection.

\section{Late responses to DHT injection}

The present study shows different responses to DHT injection into female OVX mice between early and late time point, except for differentiation (Sparc and Popdc2). The late responses to DHT treatment are 1) reduction of Myh2; 2) decrease in transcripts related to mitochondrial function such as amino acids supply to the TCA cycle (glutamate oxaloacetate transaminase 1 and 2), oxidative phosphorylation (MtNd3, EST Ndufb1, Ndufa7, Ndufs3, Cox17, and MtCo3), and ATP production (Atp5al and Atp5b); and 3) suppression of transcripts involved in cell proliferation (SGT1 suppressor of G2 allele of SKP1, Sugt1 and myeloid leukemia factor 1, Mlf1).

In the contractile apparatus, Myh2, Ank1, and three other transcripts were repressed by DHT. In fact, total number of SAGE tags corresponding to Myh2 was also decreased by $67 \%$. However, the total number of Myh tags was increased by $40 \%$. Thus, DHT treatment in OVX mice might restore contractile ability by altering not only muscle fiber distribution but also the amount of Myh mRNA. Ank1 may interacts with obscurin to hold in place the sarcoplasmic reticulum (SR) and the contractile apparatus (Armani et al. 2006). In striated muscle, the subcellular localization of the SR is accepted to be critical for the role of this organelle in controlling $\mathrm{Ca}^{2+}$ homeostasis in the context of the process of excitation-contraction coupling. Coincidently, the early induction of mRNA coding SR proteins (Atp2a1 and Casq1) was attenuated $24 \mathrm{~h}$ after the DHT treatment.

Another interesting finding of the late response to DHT injection is that the reduction of the total number of Myh2 was reflected in the changes in expression of genes encoding proteins related to muscle oxidative capacity. Indeed, in addition to transcripts related to TCA cycle, oxidative phosphorylation and ATP production, Fabp4 was also downregulated by DHT. FABPs enhance the transport of fatty acids from cell membrane to the site of oxidation, i.e. mitochondria, and to the site of esterification into intramyocellular triglycerol (IMTG). The failure in controlling uptake and oxidation of free fatty acids as well as the turnover of IMTG pool may result in pathological metabolic processes such as attenuated glucose uptake (Pan et al. 1997). Thus, both acute and chronic effects of androgen treatment on insulin sensitivity and resistance in female as well as the molecular mechanisms of the chronic treatment of androgen need to be clarified.

Sugtl is required for both the $G_{1} / S$ and $G_{2} / M$ transitions in the cell cycle (Kitagawa et al. 1999). Mlf1 inhibits erythropoietin-induced cell cycle exit and suppressed a rise in the cell cycle inhibitor p27 $7^{\mathrm{Kip} 1}$ (Winteringham et al. 2004). Moreover, mannoside acetylglucosaminyl transferase 3 (Mgat3) promotes cell proliferation (Yang et al. 2003). Thus, the modulation of these genes by DHT may decrease cell proliferation at late time point.

\section{Gender difference in DHT actions}

The common functional regulation by DHT in the female mice of the present study and male mice of our previous studies (Yoshioka et al. 2006) was an induction of transcripts involved in muscle relaxation at early time points, although male mice have shown concomitant increase in transcripts related to muscle contraction. The main difference between male and female mice in response to DHT injection was seen in transcripts related to mitochondrial function. Moreover, DHT modulated SAGE tags corresponding to proteins in contractile apparatus and glucose metabolism only in female GDX mice, whereas anabolic action of DHT has been demonstrated in male GDX mice. In five known transcripts commonly moderated by GDX and DHT in both genders, Cul4a was induced by GDX, whereas Sbp was oppositely regulated by DHT. Collectively, these results clearly show the gender differences in DHT actions on skeletal muscle. These may, in part, be due to the different skeletal muscle profile observed in male and female mice as well as modulations of coactivator and corepressor of AR such as Iqwd1 and Aes by OVX and DHT. In addition, the present study demonstrated, for the first time, the molecular mechanisms underlining acute androgen actions in female skeletal muscle using a transcriptomic method. The identification of several AREs found in the androgen-modulated genes reinforces the idea that these transcripts are regulated by androgen. 
The soy-based diet used in the present and our previous (Yoshioka et al. 2006) studies contains $<350 \mu \mathrm{g} / \mathrm{g}$ of phytoestrogens (Owens et al. 2003), which is a sufficient level to induce estrogenic effects in endocrine disruptor studies (Thigpen et al. 2004). However, the Organization for Economic Cooperative Development study (Owens $e t$ al. 2003) has concluded that the levels of phytoestrogens are acceptable for evaluation of molecular and cellular hormonal endpoints. Moreover, Barros et al. (2006) have reported that treatment with ER $\beta$ agonist in aromatase-knockout mice decreases GLUT4 expression in the skeletal muscle. Both ER $\alpha$ and ER $\beta$ are expressed in human skeletal muscle at the mRNA level, whereas only ER $\beta$ has been detected at the protein level (Wiik et al. 2003). Genistein, one of the major isoflavones in the soy protein, binds to $\mathrm{ER} \beta$ with much higher affinity than to $\mathrm{ER} \alpha$ (Kuiper et al. 1998). Thus, if there was a considerable amount of phytoestrogens in plasma and ER $\beta$ expression was induced by OVX, the Glut4 expression might have been suppressed in both OVX and OVX + DHT groups when compared with intact group with similar response between OVX and OVX + DHT groups. However, this was not the case in the present study. If ER $\beta$ expression was suppressed by OVX, the effects of phytoestrogens would have been minimum. Moreover, we found ARE in Glut4, and DHT induced its expression in the skeletal muscle of female mice. Taken together, it seems that the effects of DHT are not masked by dietary phytoestrogens in the present study. Nevertheless, a transcriptomic study of androgen actions in old female mice accessed to estrogens-free diet will merit further investigation.

\section{Acknowledgements}

We would like to thank all the research assistants and investigators involved in the ATLAS project. M Y is supported by the Heart and Stroke Foundation of Canada (HSFC), the Canadian Institute of Health Research (CIHR), and the Canadian Diabetes Association (CDA) as a postdoctoral fellow. J St-A is an investigator supported by the Fonds de la recherche en santé du Québec (FRSQ). This work was supported by Genome Québec and Genome Canada. The authors declare that there is no conflict of interest that would prejudice the impartiality of this scientific work.

\section{References}

Adams MD, Kerlavage AR, Fleischmann RD, Fuldner RA, Bult CJ, Lee NH, Kirkness EF, Weinstock KG, Gocayne JD, White O et al. 1995
Initial assessment of human gene diversity and expression patterns based upon 83 million nucleotides of cDNA sequence. Nature 377 $3-174$.

Allen DL, Harrison BC, Maass A, Bell ML, Byrnes WC \& Leinwand LA 2001 Cardiac and skeletal muscle adaptations to voluntary wheel running in the mouse. Journal of Applied Physiology 90 1900-1908.

Armani A, Galli S, Giacomello E, Bagnato P, Barone V, Rossi D \& Sorrentino V 2006 Molecular interactions with obscurin are involved in the localization of muscle-specific small ankyrin 1 isoforms to subcompartments of the sarcoplasmic reticulum. Experimental Cell Research 312 3546-3558.

Bach D, Pich S, Soriano FX, Vega N, Baumgartner B, Oriola J, Daugaard JR, Lloberas J, Camps M, Zierath JR et al. 2003 Mitofusin-2 determines mitochondrial network architecture and mitochondrial metabolism. A novel regulatory mechanism altered in obesity. Journal of Biological Chemistry 278 17190-17197.

Barros RP, Machado UF, Warner M \& Gustafsson JA 2006 Muscle GLUT4 regulation by estrogen receptors ER $\beta$ and ER $\alpha$. PNAS 103 $1605-1608$

Bottinelli R \& Reggiani C 2000 Human skeletal muscle fibres: molecular and functional diversity. Progress in Biophysics and Molecular Biology 73 195-262.

Breher SS, Mavridou E, Brenneis C, Froese A, Arnold HH \& Brand T 2004 Popeye domain containing gene 2 (Popdc2) is a myocytespecific differentiation marker during chick heart development. Developmental Dynamics 229 695-702.

Butz N, Ruetz S, Natt F, Hall J, Weiler J, Mestan J, Ducarre M, Grossenbacher R, Hauser P, Kempf D et al. 2005 The human ubiquitin-conjugating enzyme Cdc34 controls cellular proliferation through regulation of p27Kip1 protein levels. Experimental Cell Research 303 482-493.

Chatterjee I, Gross SR, Kinzy TG \& Chen KY 2006 Rapid depletion of mutant eukaryotic initiation factor $5 \mathrm{~A}$ at restrictive temperature reveals connections to actin cytoskeleton and cell cycle progression. Molecular Genetics and Genomics 275 264-276.

Cho WJ, Kim EJ, Lee SJ, Kim HD, Shin HJ \& Lim WK 2000 Involvement of SPARC in in vitro differentiation of skeletal myoblasts. Biochemical and Biophysical Research Communications 271 630-634.

Dinel S, Bolduc C, Belleau P, Boivin A, Yoshioka M, Calvo E, Piedboeuf B, Snyder EE, Labrie F \& St-Amand J 2005 Reproducibility, bioinformatic analysis and power of the SAGE method to evaluate changes in transcriptome. Nucleic Acids Research 33 21-28.

Dionne IJ, Kinaman KA \& Poehlman ET 2000 Sarcopenia and muscle function during menopause and hormone-replacement therapy. Journal of Nutrition, Health and Aging 4 156-161.

Glass DJ 2005 Skeletal muscle hypertrophy and atrophy signaling pathways. International Journal of Biochemistry and Cell Biology $\mathbf{3 7}$ 1974-1984.

Hallauer PL \& Hastings KE 2002 Coregulation of fast contractile protein transgene and glycolytic enzyme expression in mouse skeletal muscle. American Journal of Physiology. Cell Physiology 282 C113-C124.

van Hateren N, Belsham A, Randall V \& Borycki AG 2005 Expression of avian groucho-related genes ( Grgs) during embryonic development. Gene Expression Patterns 5 817-823.

Hayasaki H, Shimada M, Kanbara K \& Watanabe M 2001 Regional difference in muscle fiber type and glucose uptake of mouse gastrocnemius at rest. Cellular and Molecular Biology $\mathbf{4 7}$ OL135-OL140 (Online Pub).

Heuze ML, Guibal FC, Banks CA, Conaway JW, Conaway RC, Cayre YE, Benecke A \& Lutz PG 2005 ASB2, is an Elongin BC-interacting protein that can assemble with Cullin 5 and Rbx1 to reconstitute an E3 ubiquitin ligase complex. Journal of Biological Chemistry 280 5468-5474.

Higa LA, Yang X, Zheng J, Banks D, Wu M, Ghosh P, Sun H \& Zhang H 2006 Involvement of CUL4 ubiquitin E3 ligases in regulating CDK inhibitors Dacapo/p27Kip1 and cyclin E degradation. Cell Cycle $\mathbf{5}$ $71-77$. 
Jokic N, Gonzalez de Aguilar JL, Dimou L, Lin S, Fergani A, Ruegg MA, Schwab ME, Dupuis L \& Loeffler JP 2006 The neurite outgrowth inhibitor Nogo-A promotes denervation in an amyotrophic lateral sclerosis model. EMBO Reports 7 1162-1167.

Kenny AM, Dawson L, Kleppinger A, Iannuzzi-Sucich M \& Judge JO 2003 Prevalence of sarcopenia and predictors of skeletal muscle mass in nonobese women who are long-term users of estrogenreplacement therapy. Journals of Gerontology. Series A, Biological Sciences and Medical Sciences 58 M436-M440.

Kitagawa K, Skowyra D, Elledge SJ, Harper JW \& Hieter P 1999 SGT1 encodes an essential component of the yeast kinetochore assembly pathway and a novel subunit of the SCF ubiquitin ligase complex. Molecular Cell 4 21-33.

Kovacina KS, Park GY, Bae SS, Guzzetta AW, Schaefer E, Birnbaum MJ \& Roth RA 2003 Identification of a proline-rich Akt substrate as a 14-3-3 binding partner. Journal of Biological Chemistry 278 10189-10194.

Kuiper GG, Lemmen JG, Carlsson B, Corton JC, Safe SH, van der Saag PT, van der Burg B \& Gustafsson JA 1998 Interaction of estrogenic chemicals and phytoestrogens with estrogen receptor beta. Endocrinology 139 4252-4263.

Lash AE, Tolstoshev CM, Wagner L, Schuler GD, Strausberg RL, Riggins GJ \& Altschul SF 2000 SAGEm, map: a public gene expression resource. Genome Research 10 1051-1060.

Liang F, Liang J, Wang WQ, Sun JP, Udho E \& Zhang ZY 2006 PRL3 promotes cell invasion and proliferation by down-regulation of Csk leading to Src activation. Journal of Biological Chemistry 282 5413-5419.

Lillioja S, Young AA, Culter CL, Ivy JL, Abbott WG, Zawadzki JK, YkiJarvinen H, Christin L, Secomb TW \& Bogardus C 1987 Skeletal muscle capillary density and fiber type are possible determinants of in vivo insulin resistance in man. Journal of Clinical Investigation $\mathbf{8 0}$ $415-424$.

Magnusson C, Svensson A, Christerson U \& Tagerud S 2005 Denervation-induced alterations in gene expression in mouse skeletal muscle. European Journal of Neuroscience 21 577-580.

Mazer NA \& Shifren JL 2003 Transdermal testosterone for women: a new physiological approach for androgen therapy. Obstetrical and Gynecological Survey $\mathbf{5 8}$ 489-500.

Morley JE 2001 Testosterone replacement in older men and women. Journal of Gender-Specific Medicine 4 49-53.

Morley JE \& Perry HM, III. 2003 Androgens and women at the menopause and beyond. Journals of Gerontology. Series A, Biological Sciences and Medical Sciences 58 M409-M416.

Nilsson EC, Long YC, Martinsson S, Glund S, Garcia-Roves P, Svensson LT, Andersson L, Zierath JR \& Mahlapuu M 2006 Opposite transcriptional regulation in skeletal muscle of AMP-activated protein kinase gamma3 R225Q transgenic versus knock-out mice. Journal of Biological Chemistry 281 7244-7252.

Nishimura K, Murozumi K, Shirahata A, Park MH, Kashiwagi K \& Igarashi K 2005 Independent roles of eIF5A and polyamines in cell proliferation. Biochemical Journal 385 779-785.

Notelovitz M 2002 Androgen effects on bone and muscle. Fertility and Sterility 77 S34-S41.

Owens W, Ashby J, Odum J \& Onyon L 2003 The OECD program to validate the rat uterotrophic bioassay. Environmental Health Perspectives 111 1559-1567.

Pan DA, Lillioja S, Kriketos AD, Milner MR, Baur LA, Bogardus C, Jenkins AB \& Storlien LH 1997 Skeletal muscle triglyceride levels are inversely related to insulin action. Diabetes 46 983-988.

Pellegrino MA, Brocca L, Dioguardi FS, Bottinelli R \& D'Antona G 2005 Effects of voluntary wheel running and amino acid supplementation on skeletal muscle of mice. European Journal of Applied Physiology 93 655-664.

Polderman KH, Gooren LJ, Asscheman H, Bakker A \& Heine RJ 1994 Induction of insulin resistance by androgens and estrogens. Journal of Clinical Endocrinology and Metabolism 79 265-271.
Rajavashisth TB, Taylor AK, Andalibi A, Svenson KL \& Lusis AJ 1989 Identification of a zinc finger protein that binds to the sterol regulatory element. Science $\mathbf{2 4 5}$ 640-643.

Rincon J, Holmang A, Wahlstrom EO, Lonnroth P, Bjorntorp P, Zierath JR \& Wallberg-Henriksson H 1996 Mechanisms behind insulin resistance in rat skeletal muscle after oophorectomy and additional testosterone treatment. Diabetes 45 615-621.

Rivera-Woll LM, Papalia M, Davis SR \& Burger HG 2004 Androgen insufficiency in women: diagnostic and therapeutic implications. Human Reproduction Update 10 421-432.

Roth SM, Ferrell RE, Peters DG, Metter EJ, Hurley BF \& Rogers MA 2002 Influence of age, sex, and strength training on human muscle gene expression determined by microarray. Physiological Genomics 10 181-190.

Seo DW, Li H, Guedez L, Wingfield PT, Diaz T, Salloum R, Wei BY \& Stetler-Stevenson WG 2003 TIMP-2, mediated inhibition of angiogenesis: an MMP-independent mechanism. Cell 114 171-180.

Sheffield-Moore M, Paddon-Jones D, Casperson SL, Gilkison C, Volpi E, Wolf SE, Jiang J, Rosenblatt JI \& Urban RJ 2006 Androgen therapy induces muscle protein anabolism in older women. Journal of Clinical Endocrinology and Metabolism 91 3844-3849.

Shimizu K, Chen W, Ashique AM, Moroi R \& Li YP 2003 Molecular cloning, developmental expression, promoter analysis and functional characterization of the mouse CNBP gene. Gene 307 51-62.

Simon D, Charles MA, Lahlou N, Nahoul K, Oppert JM, GouaultHeilmann M, Lemort N, Thibult N, Joubert E, Balkau B et al. 2001 Androgen therapy improves insulin sensitivity and decreases leptin level in healthy adult men with low plasma total testosterone: a 3-month randomized placebo-controlled trial. Diabetes Care $\mathbf{2 4}$ 2149-2151.

St-Amand J, Okamura K, Matsumoto K, Shimizu S \& Sogawa Y 2001 Characterization of skeletal muscle in control and immobilized legs. An overview from genetic engineering. FASEB Journal 15 684-692.

Sun B, Jeyaseelan K, Chung MC, Tan TW, Chock PB \& Teo TS 1997 Cloning, characterization and expression of a cDNA clone encoding rabbit ubiquitin-conjugating enzyme, E2(32k). Biochimica et Biophysica Acta 1351 231-238.

Sun Y, Zhang J, Kraeft SK, Auclair D, Chang MS, Liu Y, Sutherland R, Salgia R, Griffin JD, Ferland LH et al. 1999 Molecular cloning and characterization of human trabeculin- $\alpha$, a giant protein defining a new family of actin-binding proteins. Journal of Biological Chemistry 274 33522-33530.

Takahashi K, Taira T, Niki T, Seino C, Iguchi-Ariga SM \& Ariga H 2001 DJ-1 positively regulates the androgen receptor by impairing the binding of PIASx alpha to the receptor. Journal of Biological Chemistry 276 37556-37563.

Tanner CJ, Barakat HA, Dohm GL, Pories WJ, MacDonald KG, Cunningham PR, Swanson MS \& Houmard JA 2002 Muscle fiber type is associated with obesity and weight loss. American Journal of Physiology. Endocrinology and Metabolism 282 E1191-E1196.

Thigpen JE, Setchell KD, Saunders HE, Haseman JK, Grant MG \& Forsythe DB 2004 Selecting the appropriate rodent diet for endocrine disruptor research and testing studies. ILAR Journal 45 401-416.

Tsai TC, Lee YL, Hsiao WC, Tsao YP \& Chen SL 2005 NRIP, a novel nuclear receptor interaction protein, enhances the transcriptional activity of nuclear receptors. Journal of Biological Chemistry $\mathbf{2 8 0}$ 20000-20009.

Velculescu VE, Zhang L, Vogelstein B \& Kinzler KW 1995 Serial analysis of gene expression. Science 270 484-487.

Villena JA, Hock MB, Chang WY, Barcas JE, Giguere V \& Kralli A 2007 Orphan nuclear receptor estrogen-related receptor $\alpha$ is essential for adaptive thermogenesis. PNAS 104 1418-1423. 
Vlahopoulos S, Zimmer WE, Jenster G, Belaguli NS, Balk SP, Brinkmann AO, Lanz RB, Zoumpourlis VC \& Schwartz RJ 2005 Recruitment of the androgen receptor via serum response factor facilitates expression of a myogenic gene. Journal of Biological Chemistry 280 7786-7792.

Wang H, Zhao LN, Li KZ, Ling R, Li XJ \& Wang L $2006 a$ Overexpression of ribosomal protein L15 is associated with cell proliferation in gastric cancer. BMC Cancer 691.

Wang H, Zhai L, Xu J, Joo HY, Jackson S, Erdjument-Bromage H, Tempst P, Xiong Y \& Zhang Y 2006b Histone H3 and H4 ubiquitylation by the CUL4-DDB-ROC1 ubiquitin ligase facilitates cellular response to DNA damage. Molecular Cell 22 383-394.

Warnock JK, Bundren JC \& Morris DW 1997 Female hypoactive sexual desire disorder due to androgen deficiency: clinical and psychometric issues. Psychopharmacology Bulletin 33 761-766.

Welle S, Bhatt K \& Thornton CA 2000 High-abundance mRNAs in human muscle: comparison between young and old. Journal of Applied Physiology 89 297-304.

Wiik A, Glenmark B, Ekman M, Esbjornsson-Liljedahl M, Johansson O, Bodin K, Enmark E \& Jansson E 2003 Oestrogen receptor $\beta$ is expressed in adult human skeletal muscle both at the mRNA and protein level. Acta Physiologica Scandinavica 179 381-387.

Winteringham LN, Kobelke S, Williams JH, Ingley E \& Klinken SP 2004 Myeloid leukemia factor 1 inhibits erythropoietin-induced differentiation, cell cycle exit and p27Kipl accumulation. Oncogene 23 5105-5109.
Yamauchi T, Nio Y, Maki T, Kobayashi M, Takazawa T, Iwabu M, OkadaIwabu M, Kawamoto S, Kubota N \& Kubota T et al. Targeted disruption of AdipoR1 and AdipoR2 causes abrogation of adiponectin binding and metabolic actions. Nature Medicine (in press).

Yang X, Tang J, Rogler CE \& Stanley P 2003 Reduced hepatocyte proliferation is the basis of retarded liver tumor progression and liver regeneration in mice lacking $N$-acetylglucosaminyltransferase III. Cancer Research 63 7753-7759.

Yoshioka M, Tanaka H, Shono N, Snyder EE, Shindo M \& St-Amand J 2003 Serial analysis of gene expression in the skeletal muscle of endurance athletes compared to sedentary men. FASEB Journal 17 $1812-1819$

Yoshioka M, Boivin A, Ye P, Labrie F \& St-Amand J 2006 Effects of dihydrotestosterone on skeletal muscle transcriptome in mice measured by serial analysis of gene expression. Journal of Molecular Endocrinology 36 247-259.

Yu X, Li P, Roeder RG \& Wang Z 2001 Inhibition of androgen receptormediated transcription by amino-terminal enhancer of split. Molecular and Cellular Biology 21 4614-4625.

Zhao W, Frank KF, Chu G, Gerst MJ, Schmidt AG, Ji Y, Periasamy M \& Kranias EG 2003 Combined phospholamban ablation and SERCAla overexpression result in a new hyperdynamic cardiac state. Cardiovascular Research $\mathbf{5 7} 71-81$.

Received in final form 18 April 2007

Accepted 28 May 2007

Made available online as an Accepted Preprint 31 May 2007 